\title{
Case management intervention of High Users of the Emergency Department of a Portuguese hospital: a before-after design analysis
}

\section{Simão Gonçalves}

Value for Health CoLAB

Francisco Von Hafe ( $\square$ francisco.vonhafe@vohcolab.org )

Value for Health CoLAB

Flávio Martins

Value for Health CoLAB

Carla Menino

Hospital Garcia de Orta

Maria José Guimarães

Unidade de Saúde Familiar Cova da Piedade

Andreia Mesquita

Hospital Garcia de Orta

Susana Sampaio

Hospital Garcia de Orta

Ana Rita Londral

Value for Health CoLAB

\section{Research Article}

Keywords: Case management, Integrated care, High users, Emergency department, Costs, Healthcare system sustainability

Posted Date: October 21st, 2021

DOI: https://doi.org/10.21203/rs.3.rs-991452/v1

License: (c) (i) This work is licensed under a Creative Commons Attribution 4.0 International License.

Read Full License 


\title{
Case management intervention of High Users of the Emergency Department of a Portuguese hospital: a before-after design analysis
}

\author{
Simão Gonçalves ${ }^{1,2}$, Francisco von Hafe ${ }^{1,3^{*}}$, Flávio Martins ${ }^{1,6}$, Carla Menino ${ }^{4}$, Maria José Guimarães ${ }^{5}$, \\ Andreia Mesquita ${ }^{4}$, Susana Sampaio ${ }^{4}$ and Ana Rita Londral ${ }^{1,3}$
}

\author{
*Correspondence: \\ francisco.vonhafe@vohcolab.org \\ ${ }^{1}$ Value for Health CoLAB, \\ Universidade Nova de Lisboa, \\ Lisboa, Portugal \\ Full list of author information is \\ available at the end of the article
}

\begin{abstract}
Background: Emergency department (ED) High users (HU), defined as having more than ten visits to the ED per year, are a small group of patients that use a significant proportion of ED resources. The High Users Resolution Group (GRHU) identifies and provides care to $\mathrm{HU}$ to improve their health situation and reduce their visit frequency to the ED by delivering patient-centered, case management integrated care.
\end{abstract}

Objectives: The main objective of this study was to measure the impact in terms of hospital visits of the GRHU intervention. Additionally, we aim to compare the program costs against its potential savings or additional costs. Finally, we intend to study the impact of the intervention across different groups of patients.

Methods: We studied The changes triggered by the GRHU program in a retrospective non-controlled before-after analysis of patients' hospital utilization data on six and 12-month windows from the first appointment. The GRHU team provided the patients' and cost data.

Results: A total of $238 \mathrm{ED} \mathrm{HU}$ were intervened. A sample of 88 patients was analyzed on the 12-month window as they fulfilled all inclusion criteria. This intervention was associated with a statistically significant reduction of $51 \%$ in ED use and hospitalizations, and a non-statistically significant increase in the total number of outpatient appointments. Overall costs reduced $43.56 \%$. We estimated the intervention costs to be $€ 162,847.82$. The net cost saving was $€ 104,305.25$. The program's Return on Investment (ROI) was estimated to be $€ 2.3$.

Conclusions: Patient-centered case management for ED HU seems to effectively reduce ED visits and hospitalizations, leading to the more appropriate use of resources.

Keywords: Case management; Integrated care; High users; Emergency department; Costs; Healthcare system sustainability

\section{Background}

Emergency Department (ED) High Users (HU) are a small group of patients that use a significant proportion of ED resources through multiple recurrent admissions. $[1,2,3]$.

It is estimated that $\mathrm{HU}$ "comprise $4.5 \%$ to $8 \%$ of all ED patients while accounting for $21 \%$ to $28 \%$ of all visits" [4]. In Portugal, patients that visited at least four times a year the ED represented, in $2015,12 \%$ of the number of ED users, but $35.9 \%$ of 
the total ED episodes [5]. HU contributes to ED crowding [6, 7, 8, 9], resulting in a reduction in quality of care, increased waiting times, and increased healthcare professionals' stress $[2,10]$. Regular admissions to the ED suggest that the ED is not an excellent place to treat these patients (for their clinical and social needs) $[11,10,12,13]$. The rise of ED crowding problems generated by this behaviour may compromise the access to the ED for patients with life-threatening situations whose condition will deteriorate if not treated on time and whose care can be detracted due to ED HU $[14,15,16,10,13,17]$. Additionally, HU places a disproportionately high burden on the healthcare system due to its elevated resource use, which leads to excessive hospital costs $[12,18,19]$. Hence, maintaining the dimension of the ED to treat $\mathrm{HU}$ can be a waste of resources [13]. ED HU also recur more to other non-emergency care services than non-high users [12, 20].

To improve the quality of care (in ED or primary care), the health status of ED $\mathrm{HU}$, and their high number of ED visits, it is necessary to understand the characteristics of these patients. They often have complex healthcare needs that are not optimally managed in an ED setting that provides episodic and discontinuous care $[1,16,13,20,19]$. Literature reports that psychiatric and physical conditions, chronic diseases, advanced age, lack of family support, substance abuse, socioeconomic difficulties, and demographic and socio-cultural characteristics impact ED use $[1,21,2,11,6,15,10,22,12,18,20,17,23]$. Furthermore, high ED users report higher mortality, worse health outcomes, and status [6, 12, 20, 24, 3].

Hence, interventions are necessary to reduce the number of avoidable ED visits, reducing the total cost associated with these patients [18, 25]. To be successful, interventions should focus on a clinical perspective and social, emotional, economic, and environmental aspects [14]. Hence, studies suggest interventions should be specifically targeted to each patient (e.g., Case Manager (CM)). One possible strategy is care integration implemented by a multidisciplinary team. This intervention may reduce the number of $\mathrm{ED}$ visits by preventing situations that require emergent care $[11,6,15,16]$. Case management promotes continuous, not episodic care [25]. This strategy has proven a variety of promising results, such as increased satisfaction, quality of life, and reduced costs $[11,22]$, positively impacting the healthcare systems [25]. Other types of interventions have also presented promising preliminary results $[22]$.

\section{Intervention}

In 2016, a joint-venture between Hospital Garcia de Orta (HGO) and the Agrupamento de Centros de Saúde Almada-Seixal (ACES - Almada-Seixal) created a program to provide case management interventions to HU of HGO. High Users Resolution Group Program (GRHU) is a multidisciplinary team that identifies and provides care to $\mathrm{HU}$ to improve their health status and reduce their visit frequency to the ED. GRHU addresses the healthcare and social needs of HU by delivering patient-centered, case management interventions [26]. The program's team is composed of four social workers, six doctors, and four nurses. Their workflow includes the following responsibilities: i) to discuss potential patients to include in the program; ii) to discuss and plan personalized steps to tackle the situation of each HU included in the program (Integrated Case Plan (ICP)); iii) to assign a 
$\mathrm{CM}$ to each $\mathrm{HU}$ to implement the ICP through outpatient consultations (named Multidisciplinary High Users Consultation (MHUC)). Throughout June 2016 and June 2020, the GRHU team performed, on average, five MHUC consultations per month.

\section{Goals of this study}

The main goal of this study is to measure the impact of the GRHU intervention on ED admissions. More specifically, to assess whether a $\mathrm{HU}$ has fewer visits to the ED after being included in the program. Additionally, we intend to provide an overall analysis of the impact of the intervention on different hospital services: outpatient visits and inpatient stays. Complementary to this analysis, we intend to study the impact of this intervention regarding the program costs against the potential savings or additional costs. Finally, we intend to study the impact of the intervention across patient groups to help the GRHU team better understand which patients may have better or worse outcomes from the intervention.

\section{Methodology}

\section{Study design}

To study the impact of the GRHU intervention, we performed a retrospective noncontrolled before-after analysis of patients' ED visits data on six and 12-month windows from the intervention. The 6 or 12 months before the first appointment was then defined as the before-period, while the 6 or 12 months after was the afterperiod.

\section{Study setting and population}

We conducted this study at the HGO, a public hospital located in Almada, Portugal, with approximately 164 thousand ED admissions in 2020 [27]. Between June 2017 and July 2020, GRHU reported 972 HU (patients with over ten ED admissions in a single year at a given time). During this timeline, 238 of these patients were included in the GRHU program.

\section{Inclusion criteria}

To be included in this analysis, we used the following inclusion-exclusion criteria:

- The patient must have admission data (ED visits, outpatient consultations, or inpatient stays) throughout the entire period of analysis. We controlled this by assuring that the patient has at least one admission before the "beforewindow";

- The patient cannot have died during the after-period;

- The patient's before-after window must not include data after $29^{\text {th }}$ February 2020. The HU's ED admission data (comprising all $972 \mathrm{HU}$ ) has dropped significantly after this date (Figure 1). After discussions with the GRHU

team, it was concluded likely to be the effect of Portugal entering a state of emergency due to the COVID-19 pandemic at the beginning of March 2020. 
Data analysis

HGO Ethical Committee approved this study. Anonymised data from patients that were HU between 2016 and March 2020 was made available for the study. All patients that met the inclusion criteria were included in the analysis, independently of their treatment engagement. We performed one-tailed paired t-tests for the reduction in the mean to confirm the statistical significance of the before-after changes in the hospital services utilization.

Some studied parameters were grouped into clinical categories when possible to reduce granularity and find clinically actionable patterns. Each ED visit contains a principal diagnosis assigned to the patient, classified under the ICD Ninth Revision (ICD-9) code structure [28]. This coding structure contains 19 chapters that aggregate all the ICD-9 diagnoses. Therefore, we grouped the ED visits by ICD9 chapters. We grouped inpatient hospitalization and outpatient visits by clinical specialty.

We also assessed demographic characteristics of the patients to profile them: age, gender, and economic status.

\section{Economic Analysis}

The GRHU program savings were estimated as the difference between the costs before and after the intervention per patient in the 12 or 6 months window, using the HGO perspective. The included cost categories were: ED visits, hospitalizations, and outpatient appointments. We calculated the healthcare resources usage variation costs using the hospital's Long-term Contract Program (2017-2019), where the cost

of each clinical procedure is based on the expected cost for the hospital for treating it.

Regarding the GRHU intervention costs, the hospital provided the number of hours per week devoted by each GRHU team member (including the time devoted to appointments with patients and the necessary time to prepare them) and their monthly salary. We assumed that the number of weekly hours devoted to the program was the same for every 52 weeks of the year. We computed the cost of each Human Resource (HR) per hour by dividing the number of working hours per month (assumed to be 140 hours, 35 hours per week) by their monthly salary. However, as it is estimated that costs with $\mathrm{HR}$ represent $60 \%$ of total operating costs [29], we addedd $40 \%$ of the costs (that represent other direct and indirect costs) with HR were added.

The ROI associated with the participation in the GRHU intervention was estimated as the ratio between the savings generated and the cost of the GRHU intervention [15]. If the ROI estimations are above one euro, more than one euro was saved due to GRHU intervention. All monetary values are in Euros as of 2020.

\section{Results}

Sample Selection and Characteristics

A total of 238 adult patients were intervened between the $26^{\text {th }}$ of June 2016 and the $4^{\text {th }}$ of June 2020. Out of the 238 patients, the inclusion-exclusion criteria selected 152 patients for the 6 -month before-after analysis and 88 patients for the 12 -month analysis (Figure 2). 
From this point on, we will mainly present the results for the 12 -month analysis while the 6-month will be left in the Appendix. The 12-month window was the object of most interest to the GRHU team during the regular meetings, and the findings between both analyses do not have significant differences.

The sample of the 88 patients included in the twelve-month window analysis was composed of males (58\%). The median age at the first episode in the data is 58 years old. Most patients were in a situation of economic insufficiency (57\%) (Table 1).

ED utilization

GRHU program leads to a statistically significant $51 \%$ reduction in the number of ED visits for the 12 months analysis. The median number of ED visits reduced from 14 to 7 , with values ranging between 8 and 45 in the before window and between 0 and 32 in the after one. (Table 2). Hence, the GRHU program was successful in targeting its primary goal: reduce ED utilization. The most common diagnostic throughout the analyses period was given by the codes 786 and 300 ("Symptoms involving respiratory system and other chest symptoms" and "Anxiety, dissociative and somatoform disorders", respectively).

We further study The ED episodes across the Manchester triage system colors. The reductions for the twelve-month window are reported in Table 3. All levels registered a decrease in the number of ED visits. However, the decrease was only statistically significant in the yellow, green, and orange levels $(58 \%, 52 \%$, and $37 \%$, respectively).

Furthermore, by grouping the main diagnostic of each ED visit into the ICD9 chapters, we reduced granularity from 476 unique diagnostic codes to just 19 chapters. Table 4 contains the episode reduction across the ICD-9 Chapters.

\section{Other hospital services utilization}

Regarding inpatient stays, a 51\% reduction in the number of episodes (Table 2) corresponding to a median reduction from 1 to 0 episodes (the before window with patients ranging between 0 and 8 episodes while the after window ranged between 0 and 5$)$.

Inpatient stays are associated with a clinical specialty group related to the nature of the episode (psychiatry, surgery, or others). Therefore we also analyzed the episode reduction across these groups and present it in Table 5. The reduction was statistically significant in general surgery and psychiatry (78\% and 69\%, respectively). The average Length of Stay (LOS) before the intervention was 13.9 days, and this number decreased to 9.4 days in the after-period, resulting in a $34 \%$ reduction in LOS.

Regarding the outpatient appointments (Table 2), the GRHU interventions were registered as outpatient appointments in the data. Therefore we split both views of the outpatient appointments: all appointments in the data vs. not including GRHU appointments. If we do not include the GRHU interventions, we observe a $3 \%$ decrease however, not statistically significant. If we add the number of GRHU appointments, the total number of outpatient appointments grows by $41 \%$ (Table 
5 ), which was not statistically significant. In this scenario, the number of outpatient appointments in the 12-months window ranged between zero and 29 in the beforeperiod and 0 and 36 in the after-period).

\section{Economic Analysis}

The total cost of ED visits, outpatient consultation, and inpatient stays was calculated before and after the first GRHU appointment (Table 6) and presented results similar to the utilization of the hospital services. When analysing the differences between before and after the intervention, on the twelve-month window, as hypothesised, the total cost with these patients (88 included in the twelve-month window sample) reduced $43.56 \%$, generating a saving of $€ 184,240.59$. As expected, costs decreased in ED and inpatients stays (51.63\% and $51.79 \%$, respectively) and increased in outpatient appointments (39.34\%).

The total cost of the GRHU program for the 238 patients was $€ 162,847.82$ (€684.23 per patient). However, as in the 12 -month window, only 88 patients the total cost is $€ 79,935.34$. The net cost saving was $€ 104,305.25$. The ROI of the GRHU program was estimated to be $184,240.59 / 79,935.34$, $€ 2.3$, which means that for every $€ 1$ invested in the GRHU program, $€ 2.3$ was saved.

\section{Discussion}

The $51 \%$ reduction in ED episodes demonstrates that GRHU's program was successful, leading to a statically significant reduction in ED usage and inpatient episodes, inpatient LOS, and hospital costs. These results are similar to other case management implementations for tackling $\mathrm{HU}[30,1]$. As ED utilization influences hospital re-admissions, reducing ED visits has a spillover effect on other hospital departments, which also benefits other hospital users, as it contributes to reducing overcrowding [15, 22]. e registered an increase in outpatient appointments, but the GRHU appointments thoroughly explained it. This program seems to be costsaving, as it triggered savings of $€ 2.3$ per euro spent on the 12-month window, which is in line with similar studies [15]. It should not be expected significant cost savings as the goal is to guarantee that patients have access to the healthcare services they need and not to reduce their access to healthcare [22].

This information is crucial for understanding how performing case management interventions (which is very different from ED care) can provide adequate treatment to the complex needs of HU. Thus, reducing their necessity of returning to the ED results in reduced costs for the hospital and less crowding. Moreover, these promise results can serve as a benchmark to justify the implementation of this program at a larger scale.

GRHU intervention was successful in reducing ED episodes related to mental disorders diagnoses. Furthermore, there were high discrepancies when comparing the reductions among the ICD-9 Chapters. For example, diagnostics from "Disease of the Digestive System" experienced a reduction of $61 \%$, while "Diseases of the Respiratory System" were reduced by $32 \%$. We found that reporting the reductions by disease groups was well welcomed by the GRHU team. They acknowledged that this information provided them insights that could allow them to improve the case management program by tackling how the program dealt with patients whose 
diagnostics belong to low reduction groups. Lastly, despite the focus on reducing ED visits, inpatient stays were also positively affected by the intervention.

Despite the promising results obtained in this study, we recognize some limitations which influence their interpretation.

The underlying assumptions and weaknesses of a before-after design are well known [31, Chapter 3]. We consider two significant threats to the validity of this study. One is the history threat, in which other influential events could have affected the outcome instead of the intervention itself. This could happen, for example, due to the seasonality of the hospital ED admissions, in which the winter season usually comes with more visits. However, the seasonality risk is mitigated because the GRHU interventions were spread over three years, resulting in the before-after change being computed throughout many different periods, thus reducing the risk of seasonality and isolated events influencing the event results.

Another threat to the validity of this study is the regression to the mean. One selection criteria for assigning new patients to the GRHU program consisted of choosing the higher ED users at the time. Therefore this is, by definition, an outlier sample of the patients. Moreover, studies argue that the HU of the ED would not maintain its status in the long term. Therefore, considering these two points, we conclude that this could potentially bias our results, particularly in the 12 months before-after analysis [4].

Furthermore, selection bias issues may arise as the GRHU staff selected the included patients, for the most part, according to the highest ED usage at the time, instead of being randomly selected for the program, and therefore our findings do not necessarily represent all HU of the hospital, but instead HU. This limitation may compromise the results' generalisability, which should be considered for the specific demographic targeted here.

Moreover, the program was designed according to the need of HGO patients and the analysis according to the hospital payment scheme. Again generalization issues may arise.

Third, we did not include in the analysis all relevant costs. Due to time and COVID-19 constraints, the hospital did not provide all relevant cost information. This led to the use of different assumptions and hypotheses. Hence, the obtained results may not reflect the actual costs. However, to minimize this limitation, we presented the costs analysis to the hospital administration board members to validate all the assumptions. Furthermore, costs should be analysed from a societal perspective, assessing the impact of the intervention on other relevant stakeholders. For example, we are not including visits to other hospitals or healthcare providers. However, we expect the results of this intervention to be similar. Nonetheless, to study the impact of the intervention using the hospital perspective is critical because for the hospital to implement this intervention, it must benefit from it [22].

Finally, by only collecting the information on the number of visits to the hospital, we cannot assess the impact of the intervention on other relevant health outcomes that are impacted by the ED HU conditions. So future research should also incorporate them in their analysis. This study highlights the importance of data sharing in healthcare, following data safety and protection guidelines. It will strengthen the multidisciplinary work between clinicians, administrators, and researchers. It is a 
crucial step to conduct analysis that will enable more sustainable and higher-quality healthcare systems.

Future research should focus on developing tools that help hospital staff selecting new patients for the program, and thus optimizing their work in two ways: choosing patients that contain mainly diagnostics that experienced a high reduction in previous patients of the program and reworking the intervention to improve the reduction on diagnostic groups which do not experience a significant reduction. Moreover, a study conducted with a larger patient sample that is randomized and collects outcomes and costs in a broader perspective should be implemented.

\section{Conclusions}

The GRHU's program focused on creating a multidisciplinary team that aimed to reduce the number of ED visits of patients that went to the ED more than ten times in the previous year. The intervention led to a $51 \%$ reduction in the number of ED visits and inpatient. Moreover, when comparing the costs with the GRHU program with the saving it generated, saving of $€ 2,3$ per $€ 1$ spent were registered.

\section{Abbreviations}

ED: Emergency department; HGO: Hospital Garcia de Orta; GRHU: High Users Resolution Group Program; ICP: Integrated Case Plan; CM: Case Manager; ICD9: ICD Ninth Revision; MHUC: Multidisciplinary High Users Consultation; ROI: Return on Investment; LOS: Length of Stay; ITS: Interrupted Time Series; HU: High users; HR: Human Resource

\section{Declarations}

Acknowledgements

The authors appreciate comments from Judite Gonçalves and the Emergency Department team of Hospital Garcia de Orta.

\section{Funding}

FVH, FM, and ARL acknowledge funding from the Portuguese National Funding Agency for Science, Research, and Technology (FCT) and public ESF funding with reference LISBOA-05-3559-FSE-000003. SG acknowledges funding from DSAIPA project FrailCare.AI (DSAIPA/0106/2019/02) with the financial support of FCT.

\section{Availability of data and materials}

The data that support the findings of this study are available from Hospital Garcia de Orta, but restrictions apply to the availability of these data, which were used under license for the current study, and so are not publicly available.

\section{Ethics approval and consent to participate}

This study was approved by the Hospital Garcia de Orta Ethical Committee.

\section{Competing interests}

The authors declare that they have no competing interests. 


\section{Consent for publication}

Not applicable

\section{Authors' contributions}

All authors were involved in the study conception and design. FVH and SP collected cost data. SG, FM, ARL, FVH analyzed and interpreted study data. CM, MJG, AM discussed the results. SG and FVH drafted the manuscript. FM and ARL critically revised the manuscript for important intellectual content and supervised the study. All authors read and approved the final manuscript.

\section{Author details}

${ }^{1}$ Value for Health CoLAB, Universidade Nova de Lisboa, Lisboa, Portugal. ${ }^{2}$ Nova School of Science and Technology, Nova University of Lisbon, Lisbon, Portugal. ${ }^{3}$ Comprehensive Health Research Centre (CHRC), Nova Medical School, Lisbon, Portugal. ${ }^{4}$ Hospital Garcia de Orta, EPE, Almada, Portugal. ${ }^{5}$ Unidade de Saúde Familiar Cova da Piedade, Almada, Portugal. ${ }^{6}$ Nova LINCS, Nova School of Science and Technology, Universidade Nova de Lisboa, Lisbon, Portugal.

\section{References}

1. Abello, A., Brieger, B., Dear, K., King, B., Ziebell, C., Ahmed, A., Milling, T.J.: Care plan program reduces the number of visits for challenging psychiatric patients in the ED. The American Journal of Emergency Medicine 30(7), 1061-1067 (2012). doi:10.1016/j.ajem.2011.07.002

2. Chiu, Y., Racine-Hemmings, F., Dufour, I., Vanasse, A., Chouinard, M.-C., Bisson, M., Hudon, C.: Statistical tools used for analyses of frequent users of emergency department: A scoping review. BMJ Open 9(5), 027750 (2019). Chap. Health services research. doi:10.1136/bmjopen-2018-027750

3. Blank, F.S.J., Li, H., Henneman, P.L., Smithline, H.A., Santoro, J.S., Provost, D., Maynard, A.M.: A Descriptive Study of Heavy Emergency Department Users at an Academic Emergency Department Reveals Heavy ED Users Have Better Access to Care Than Average Users. Journal of Emergency Nursing 31(2), 139-144 (2005). doi:10.1016/j.jen.2005.02.008. Accessed 2021-07-08

4. LaCalle, E., Rabin, E.: Frequent users of emergency departments: The myths, the data, and the policy implications. Annals of Emergency Medicine 56(1), 42-48 (2010). doi:10.1016/j.annemergmed.2010.01.032

5. Catarino, I.P.d.S.: Utilizadores frequentes das urgências do Serviço Nacional de Saúde. PhD thesis, Faculdade de Ciências e Tecnologia e a Universidade Nova de Lisboa (September 2017)

6. Moe, J., Kirkland, S.W., Rawe, E., Ospina, M.B., Vandermeer, B., Campbell, S., Rowe, B.H.: Effectiveness of Interventions to Decrease Emergency Department Visits by Adult Frequent Users: A Systematic Review. Academic Emergency Medicine 24(1), 40-52 (2017). doi:10.1111/acem.13060. Accessed 2021-05-06

7. Lee, J.H., Park, G.J., Kim, S.C., Kim, H., Lee, S.W.: Characteristics of frequent adult emergency department users: A Korean tertiary hospital observational study. Medicine 99(18), 20123 (2020). doi:10.1097/MD.0000000000020123

8. Seguin, J., Osmanlliu, E., Zhang, X., Clavel, V., Eisman, H., Rodrigues, R., Oskoui, M.: Frequent users of the pediatric emergency department. Canadian Journal of Emergency Medicine 20(3), 401-408 (2018). doi: $10.1017 /$ cem.2017.15

9. Hunt, K.A., Weber, E.J., Showstack, J.A., Colby, D.C., Callaham, M.L.: Characteristics of Frequent Users of Emergency Departments. Annals of Emergency Medicine 48(1), 1-8 (2006). doi:10.1016/j.annemergmed.2005.12.030

10. Van den Heede, K., Van de Voorde, C.: Interventions to reduce emergency department utilisation: A review of reviews. Health Policy 120(12), 1337-1349 (2016). doi:10.1016/j.healthpol.2016.10.002. Accessed 2021-05-11

11. Hudon, C., Chouinard, M.-C., Lambert, M., Dufour, I., Krieg, C.: Effectiveness of case management interventions for frequent users of healthcare services: a scoping review. BMJ Open 6(9), 012353 (2016). doi:10.1136/bmjopen-2016-012353. Accessed 2021-05-11

12. Ruger, J.P.: Analysis of Costs, Length of Stay, and Utilization of Emergency Department Services by Frequent Users: Implications for Health Policy. Academic Emergency Medicine 11(12), 1311-1317 (2004). doi:10.1197/j.aem.2004.07.008. Accessed 2021-07-08

13. Mandelberg, J.H., Kuhn, R.E., Kohn, M.A.: Epidemiologic Analysis of an Urban, Public Emergency Department's Frequent Users. Academic Emergency Medicine 7(6), 637-646 (2000). doi:10.1111/j.1553-2712.2000.tb02037.x

14. Grimmer-Somers, K., Johnston, K., Somers, E., Luker, J., Ann Alemao, L., Jones, D.: A holistic client-centred program for vulnerable frequent hospital attenders: cost efficiencies and changed practices. Australian and New Zealand Journal of Public Health 34(6), 609-612 (2010). doi:10.1111/j.1753-6405.2010.00616.x. Accessed 2021-05-06

15. Navratil-Strawn, J.L., Hawkins, K., Wells, T.S., Ozminkowski, R.J., Hartley, S.K., Migliori, R.J., Yeh, C.S.: An Emergency Room Decision-Support Program That Increased Physician Office Visits, Decreased Emergency Room Visits, and Saved Money. Population Health Management 17(5), 257-264 (2014) doi:10.1089/pop.2013.0117. Accessed 2021-05-06

16. Soril, L.J.J., Leggett, L.E., Lorenzetti, D.L., Noseworthy, T.W., Clement, F.M.: Reducing Frequent Visits to the Emergency Department: A Systematic Review of Interventions. PLOS ONE 10(4), 0123660 (2015). doi:10.1371/journal.pone.0123660. Accessed 2021-05-06

17. Lee, J.E., Sung, J.H., Ward, W.B., Fos, P.J., Lee, W.J., Kim, J.C.: Utilization of the emergency room: impact of geographic distance. Geospatial health 1(2), 243 (2007). doi:10.4081/gh.2007.272. Accessed 2021-07-08 
18. Frost, D.W., Vembu, S., Wang, J., Tu, K., Morris, Q., Abrams, H.B.: Using the Electronic Medical Record to Identify Patients at High Risk for Frequent Emergency Department Visits and High System Costs. The American Journal of Medicine 130(5), 601-1760122 (2017). doi:10.1016/j.amjmed.2016.12.008. Accessed 2021-07-08

19. Okin, R.L., Boccellari, A., Azocar, F., Shumway, M., O'Brien, K., Gelb, A., Kohn, M., Harding, P., Wachsmuth, C.: The effects of clinical case management on hospital service use among ED frequent users. The American Journal of Emergency Medicine 18(5), 603-608 (2000). doi:10.1053/ajem.2000.9292. Accessed 2021-07-08

20. Sun, B.C., Burstin, H.R., Brennan, T.A.: Predictors and Outcomes of Frequent Emergency Department Users. Academic Emergency Medicine 10(4), 320-328 (2003). doi:10.1111/j.1553-2712.2003.tb01344.x. Accessed 2021-07-08

21. Bodenmann, P., Velonaki, V.-S., Griffin, J.L., Baggio, S., Iglesias, K., Moschetti, K., Ruggeri, O., Burnand, B., Wasserfallen, J.-B., Vu, F., Schupbach, J., Hugli, O., Daeppen, J.-B.: Case Management may Reduce Emergency Department Frequent use in a Universal Health Coverage System: a Randomized Controlled Trial. Journal of General Internal Medicine 32(5), 508-515 (2017). doi:10.1007/s11606-016-3789-9. Accessed 2021-05-11

22. Shumway, M., Boccellari, A., O'Brien, K., Okin, R.L.: Cost-effectiveness of clinical case management for ED frequent users: results of a randomized trial 26(2), 155-164. doi:10.1016/j.ajem.2007.04.021. Accessed 2021-07-08

23. Doupe, M.B., Palatnick, W., Day, S., Chateau, D., Soodeen, R.-A., Burchill, C., Derksen, S.: Frequent Users of Emergency Departments: Developing Standard Definitions and Defining Prominent Risk Factors. Annals of Emergency Medicine 60(1), 24-32 (2012). doi:10.1016/j.annemergmed.2011.11.036. Accessed 2021-07-08

24. Chan, B.T.B., Ovens, H.J.: Frequent users of emergency departments. Do they also use family physicians' services? Canadian Family Physician (2002)

25. Kumar, G.S., Klein, R.: Effectiveness of Case Management Strategies in Reducing Emergency Department Visits in Frequent User Patient Populations: A Systematic Review. The Journal of Emergency Medicine 44(3), 717-729 (2013). doi:10.1016/j.jemermed.2012.08.035. Accessed 2021-07-08

26. Kanter, J.: Clinical Case Management: Definition, Principles, Components. Psychiatric Services 40(4), 361-368 (1989). doi:10.1176/ps.40.4.361

27. de Orta, H.G.: Relatório e Contas 2019. Hospital Garcia de Orta. (2020)

28. ICD-9-CM Official Guidelines for Coding and Reporting Effective (2011)

29. Balakrishnan, K., Goico, B., Arjmand, E.M.: Applying Cost Accounting to Operating Room Staffing in Otolaryngology: Time-Driven Activity-Based Costing and Outpatient Adenotonsillectomy. Otolaryngology-Head and Neck Surgery 152(4), 684-690 (2015). doi:10.1177/0194599814568273. Accessed 2021-07-21

30. Grover, C.A., Sughair, J., Stoopes, S., Guillen, F., Tellez, L., Wilson, T.M., Gaccione, C., Close, R.J.H.: Case Management Reduces Length of Stay, Charges, and Testing in Emergency Department Frequent Users. Western Journal of Emergency Medicine: Integrating Emergency Care with Population Health 19(2) (2018). doi:10.5811/westjem.2017.9.34710

31. Guide to evaluating the effectiveness of strategies for preventing work injuries: How to show whether a safety intervention really works. (2020). doi:10.26616/NIOSHPUB2001119

\section{Figures}

Figure 1 - Timeseries of the ED admission history between June 2017 and July 2020.

Most of the series varies between 400 and 500 admissions per month, however, data after March $1^{s t}, 2020$ contains a clear steep reduction in the total number of ED episodes

Figure 2 - Exclusion steps for the before-after analysis

\section{Tables}

Table 1 Demographic Information of 3 groups of GRHU patients: all patients, those eligible for the six months analysis, and those eligible for the 12 months analysis

\begin{tabular}{ccccc}
\hline & \multicolumn{3}{c}{ Samples } \\
\cline { 3 - 5 } & & $\begin{array}{c}\text { GRHU } \\
\text { patients }\end{array}$ & $\begin{array}{c}\text { months } \\
\text { patients }\end{array}$ & $\begin{array}{c}12 \text { months } \\
\text { patients }\end{array}$ \\
\hline \multirow{2}{*}{ Age } & Average & 58.3 & 56.8 & 57.3 \\
& std & 18.2 & 17.8 & 17.7 \\
\hline \multirow{2}{*}{ Gender } & Males & 128 & 90 & 55 \\
& Females & 110 & 62 & 33 \\
\hline \multirow{3}{*}{$\begin{array}{c}\text { Payment } \\
\text { Exemption }\end{array}$} & Economic & & & \\
\multicolumn{2}{c}{ Insufficiency } & 115 & 80 & 50 \\
& Incapacity & 27 & 17 & 11 \\
& None & 95 & 54 & 27 \\
\hline
\end{tabular}


Table 212 months a before-after variation of 88 patients. * differences that passed the one-sided paired $t$-test for the reduction in mean with a $p<0.05$.

\begin{tabular}{cccc}
\hline & \multicolumn{3}{c}{ Before After Variation } \\
\hline $\begin{array}{c}\text { ED } \\
\text { episodes }\end{array}$ & 1413 & 688 & $-51 \% *$ \\
\hline $\begin{array}{c}\text { Inpatient } \\
\text { episodes }\end{array}$ & 105 & 51 & $-51 \% *$ \\
\hline Outpatient appointments & 522 & 732 & $+40 \%$ \\
\hline $\begin{array}{c}\text { Outpatient appointments } \\
\text { w/o GRHU }\end{array}$ & 522 & 508 & $-3 \%$ \\
\hline
\end{tabular}

Table 312 months before-after variation of 88 patients across Manchester triage system colors. * differences that passed the one-sided paired t-test for the reduction in mean with a $p<0.05$.

\begin{tabular}{lrrr}
\hline & BEFORE & AFTER & Variation \\
& & & \\
\hline Yellow & 584 & 248 & $-58 \%^{*}$ \\
Green & 532 & 253 & $-52 \%^{*}$ \\
Orange & 208 & 132 & $-37 \% *$ \\
Blue & 68 & 48 & $-29 \% *$ \\
White & 18 & 5 & $-72 \%$ \\
Red & 3 & 2 & $-33 \%$ \\
\hline
\end{tabular}

Table 4 Reduction across ICD-9 Chapters in the 12 months before-after analysis. * differences that passed the one-sided paired $t$-test for the reduction in mean with a $p<0.05$.

\begin{tabular}{|c|c|c|c|}
\hline & Before & After & Variation \\
\hline Diseases of the Digestive System & 54 & 21 & $-61 \% *$ \\
\hline Mental Disorders & 237 & 97 & $-59 \% *$ \\
\hline Diseases of the Genitourinary System & 121 & 52 & $-57 \% *$ \\
\hline Injury and Poisoning & 133 & 61 & $-54 \% *$ \\
\hline $\begin{array}{l}\text { Supplementary Classification of Factors } \\
\text { Influencing Health Status and } \\
\text { Contact with Health Services }\end{array}$ & 63 & 29 & $-54 \% *$ \\
\hline $\begin{array}{c}\text { Symptoms, Signs, and III-defined } \\
\text { Conditions }\end{array}$ & 331 & 169 & $-49 \% *$ \\
\hline Diseases of the Circulatory System & 95 & 52 & $-45 \% *$ \\
\hline Diseases of the Respiratory System & 98 & 67 & $-32 \% *$ \\
\hline Neoplasms & 5 & 1 & $-80 \%$ \\
\hline $\begin{array}{l}\text { Diseases of the Blood System } \\
\text { and Blood-forming Organs }\end{array}$ & 26 & 6 & $-77 \%$ \\
\hline $\begin{array}{l}\text { Supplementary Classification of External } \\
\text { Causes of Injury and Poisoning }\end{array}$ & 17 & 7 & $-59 \%$ \\
\hline $\begin{array}{l}\text { Disease of the Skin } \\
\text { and Subcutaneous Tissue }\end{array}$ & 12 & 5 & $-58 \%$ \\
\hline $\begin{array}{c}\text { Diseases of the Nervous System } \\
\text { and Sense Organs }\end{array}$ & 74 & 33 & $-55 \%$ \\
\hline $\begin{array}{l}\text { Endocrine, Nutritional and Metabolic } \\
\text { Disease and Immunity Disorders }\end{array}$ & 34 & 16 & $-53 \%$ \\
\hline $\begin{array}{l}\text { Diseases of the Musculoskeletal } \\
\text { System and Connective Tissue }\end{array}$ & 100 & 61 & $-39 \%$ \\
\hline Infectious and Parasitic Disease & 12 & 11 & $-8 \%$ \\
\hline
\end{tabular}


Table 5 Reduction across specialty grouped of inpatient stay episodes in 12 months before-after analysis. * differences that passed the one-sided paired t-test for the reduction in mean with a $p<0.05$. Results are sorted by statistically significant differences and variation

\begin{tabular}{cccc}
\hline & Before & After & Variation \\
\hline General Surgery & 18 & 4 & $-78 \%{ }^{*}$ \\
\hline Psychiatry & 16 & 5 & $-69 \%{ }^{*}$ \\
\hline Internal Medicine & 41 & 23 & $-44 \%$ \\
\hline Urology & 4 & 3 & $-25 \%$ \\
\hline Cardiology & 6 & 6 & $0 \%$ \\
\hline Nephrology & 2 & 2 & $0 \%$ \\
\hline Neurology & 1 & 1 & $0 \%$ \\
\hline Pneumology & 4 & 6 & $+50 \%$ \\
\hline
\end{tabular}

Table 6 Total Healthcare expenditure before and after the intervention for the 12-month window

\begin{tabular}{cccc}
\hline & Before Intervention & After Intervention & $\begin{array}{c}\text { Difference } \\
\mathbf{( \% )}\end{array}$ \\
\hline Total & $€ 423,004.61$ & $€ 238,764.02$ & $\begin{array}{c}-€ 184,240.59 \\
(-43.56 \%)\end{array}$ \\
\hline ED & $€ 142,742.65$ & $€ 69,045.47$ & $\begin{array}{c}-€ 73,697.18 \\
(-51.63 \%)\end{array}$ \\
\hline Outpatient Appointments & $€ 37,964.51$ & $€ 52,901.62$ & $\begin{array}{c}€ 14,937.11 \\
(39.34 \%)\end{array}$ \\
\hline Inpatient stay & $€ 242,297.45$ & $€ 116,816.93$ & $\begin{array}{c}-€ 125,480.52 \\
(-51.79 \%)\end{array}$ \\
\hline
\end{tabular}

\section{Additional Files}

Additional file 1 - Results for the analysis conducted for the 6-month window.

Tables that report the results for the 6-month window analysis 


\section{Figures}

ED episodes from 972 frequent users ( $>10$ visits/year) on a monthly basis

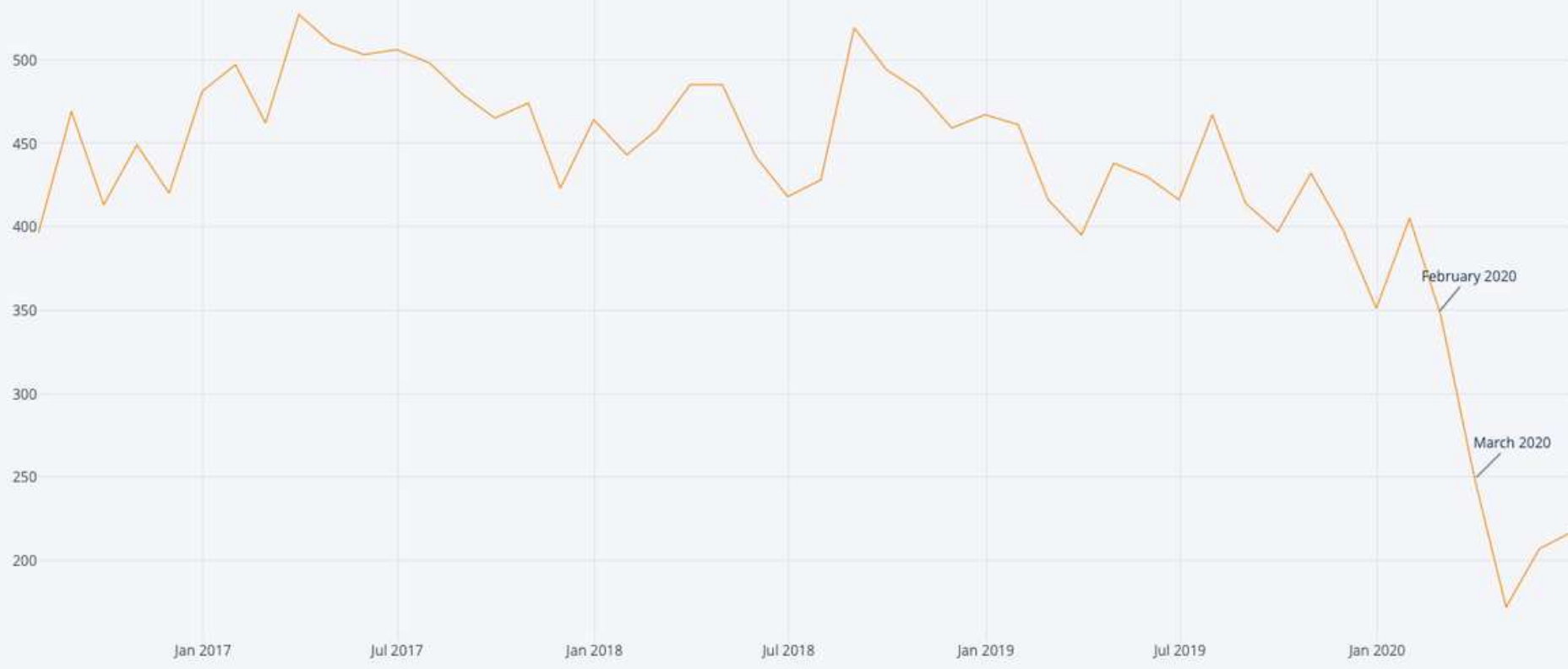

Figure 1

Timeseries of the ED admission history between June 2017 and July 2020. Most of the series varies between 400 and 500 admissions per month, however, data after March 1st, 2020 contains a clear steep reduction in the total number of ED episodes

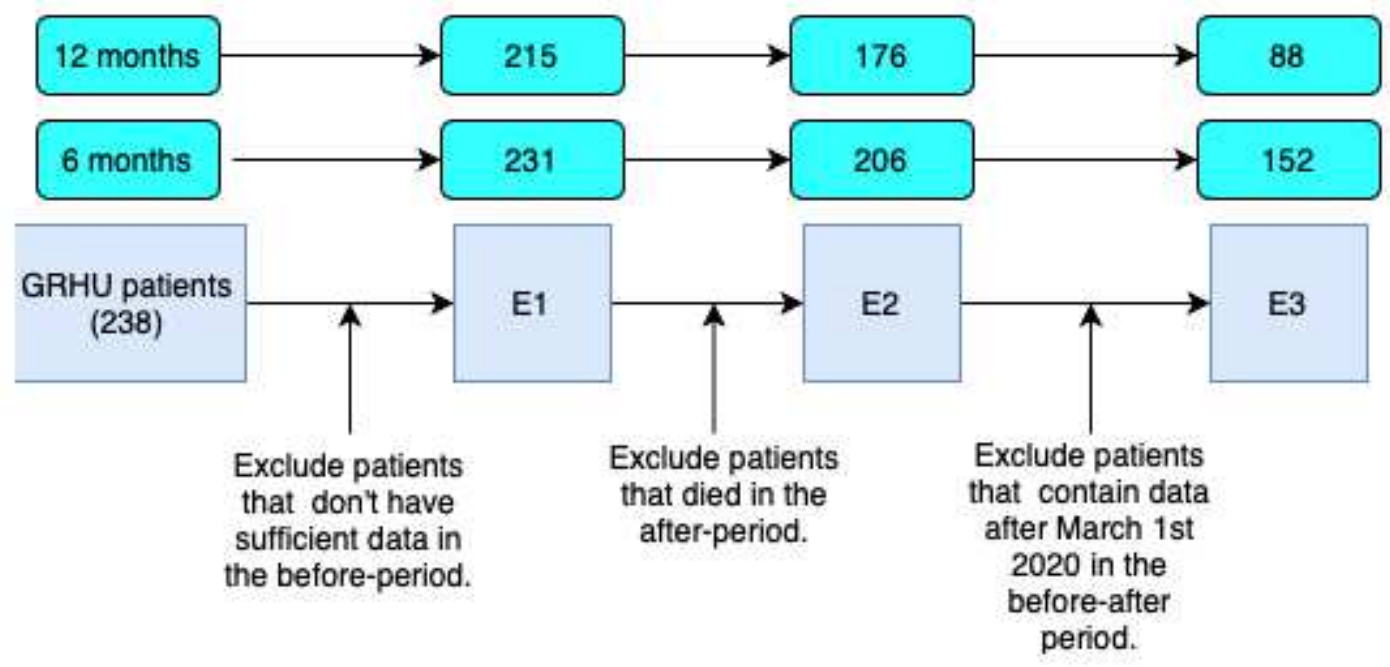

Figure 2

Exclusion steps for the before-after analysis 


\section{Supplementary Files}

This is a list of supplementary files associated with this preprint. Click to download.

- Appendix.pdf 